\title{
Validation of the Cell Cycle Arrest Biomarkers in the Diagnosis of Pregnancy Related Acute Kidney Injury
}

\author{
osama el-minshawy ${ }^{1}$, mahmoud khedr $^{1}$, ayman elsayed ${ }^{1}$, Moustafa Abu-Ella ${ }^{1}$, Fatma \\ Kamel $^{1}$, and hesham keryakos ${ }^{1}$ \\ ${ }^{1}$ Minia University Faculty of Medicine
}

May 5, 2020

\begin{abstract}
Background: Pregnancy related acute kidney injury (PRAKI) is still a common serious problem in developing countries. Insulinlike growth factor-binding protein 7 (IGFBP7) and tissue inhibitor metalloproteinases-2 (TIMP-2) can identify critically ill patients at risk for the development of severe AKI. Objectives: To identify main causes and timing of PRAKI and to study the G1 cell cycle arrest biomarkers in cases diagnosed with (PRAKI) as a diagnostic tool. Methods: 80 pregnant women diagnosed with PRAKI were recruited from a single hospital as well as 30 age-matched pregnant women with normal pregnancy participated in this study. A urine specimen was collected from all study participants with established AKI within 24 hours of ICU admission to measure IGFBP7*TIMP-2. Results: The incidence of PRAKI was 1.1\%. The most common cause of PRAKI is preeclampsia/eclampsia spectrum (61\%). Most of the cases occur in the third trimester (60\%) and postpartum period (23\%). At a cutoff $0.33 \mathrm{ng} / \mathrm{mL}$, the estimated sensitivity and specificity of urinary [TIMP-2]*[IGFBP7] in predicting PRAKI is $100 \%$ (95\% CI) with NPV and PPV are 100\%. Conclusions: Urinary [TIMP-2]*[IGFBP7] serves as a sensitive and specific biomarker in the diagnosis of PRAKI.
\end{abstract}

\section{Hosted file}

Main Text.docx available at https://authorea.com/users/299831/articles/429505-validationof-the-cell-cycle-arrest-biomarkers-in-the-diagnosis-of-pregnancy-related-acute-kidneyinjury 